\title{
Patients with emm1/T1 serotype invasive group A streptococci infections demonstrated more renal failure than patients with other serotypes: perhaps we should consider some confounders
}

\author{
Patrick M. Honore*, Leonel Barreto Gutierrez, Luc Kugener, Sebastien Redant, Rachid Attou, Andrea Gallerani and \\ David De Bels
}

We read with great interest the article by Björck et al. who concluded that in their study of critically ill patients with invasive group A streptococcal (iGAS) infections, emm1/T1 was the most dominant serotype and that patients with that serotype demonstrated more circulatory and renal failure than patients with other serotypes of iGAS [1]. We would like to make some comments. Intravenous immunoglobulins (IVIGs) are often used as a part of the treatment of iGAS [1]. We noted that $52 \%$ of the emm1/T1 serotype patients received IVIGs as compared to $28 \%$ of the patients with other serotypes [1]. The incidence of acute kidney injury (AKI) with IVIGs stabilized with glucose, maltose, D-sorbitol, mannitol, glycine, or L-proline has been found to be lower than that with sucrose-stabilized products [2]. AKI induced by sucrose-containing IVIGs is likely related to the toxic action of sucrose on the nephron, whereby excess sucrose in the kidney causes osmotic nephrosis [2, 3]. Whilst osmotic nephrosis has been reported with sucrose-free IVIGs, the incidence is much lower because the levels of these agents can be closely regulated by enzymes within the kidney [2, 4]. Similarly to sucrose, excessive glucose accumulation can have deleterious effects on the proximal tubules [5] and, since intravenous glucose infusion is known to produce a rapid increase in blood glucose and insulin levels in normal

\footnotetext{
* Correspondence: Patrick.Honore@CHU-Brugmann.be

ICU Department, Centre Hospitalier Universitaire Brugmann-Brugmann

University Hospital, Place Van Gehuchtenplein, 4, 1020 Brussels, Belgium
}

subjects, diabetic patients are at particular risk of AKI following administration of glucose-stabilized IVIGs [2]. The incidence of diabetes mellitus is not reported in the paper of Björck et al. [1]. It is possible that the increase of AKI in the emm1/T1 serotype group was due to IVIGs. It would be very interesting to know if the IVIGs given to patients in this study were sucrose-stabilized.

\section{Abbreviations \\ iGAS: Invasive group A streptococci; IVIGs: Intravenous immunoglobulins; AKI: Acute kidney injury}

\section{Acknowledgements \\ We would like to thank Dr. Melissa Jackson for the critical review of the manuscript.}

\section{Authors' contributions}

$\mathrm{PMH}, \mathrm{SR}$, and DDB designed the paper. All authors participated in drafting and reviewing. All authors read and approved the final version of the manuscript.

\section{Funding}

None.

\section{Availability of data and materials} Not applicable.

Ethics approval and consent to participate Not applicable.

\section{Consent for publication} Not applicable.

\section{Competing interests}

The authors declare to have no competing interests. 
Received: 24 June 2020 Accepted: 14 July 2020

Published online: 29 July 2020

References

1. Björck V, Påhlman LI, Bodelsson $\mathrm{M}$, et al. Morbidity and mortality in critically ill patients with invasive group A streptococcus infection: an observational study. Crit Care. 2020;24:302. https://doi.org/10.1186/s13054-020-03008-z.

2. Dantal J. Intravenous immunoglobulins: in-depth review of excipients and acute kidney injury risk. Am J Nephrol. 2013;38(4):275-84. https://doi.org/10. $1159 / 000354893$

3. Lin RY, Rodriguez-Baez G, Bhargave GA, Lin H. Intravenous gammaglobulinassociated renal impairment reported to the FDA: 2004-2009. Clin Nephrol. 2011;76:365-72.

4. Orbach $H$, Tishler M, Shoenfeld $Y$. Intravenous immunoglobulin and the kidney - a two-edged sword. Semin Arthritis Rheum. 2004;34:593-601.

5. Ochs HD, Siegel J. Stabilizers used in intravenous immunoglobulin products: a comparative review. Pharm Pract News, 2010.

\section{Publisher's Note}

Springer Nature remains neutral with regard to jurisdictional claims in published maps and institutional affiliations. 